\title{
Relationship of child perceptions of maternal pain to children's laboratory and nonlaboratory pain
}

\author{
Subhadra Evans PhD, Jennie Cl Tsao PhD, Lonnie K Zeltzer MD
}

\begin{abstract}
S Evans, JCI Tsao, LK Zeltzer. Relationship of child perceptions of maternal pain to children's laboratory and nonlaboratory pain. Pain Res Manage 2008;13(3):211-218.
\end{abstract}

Previous research has established links between parent and child pain. However, little is known about sex-specific parent-child pain relationships in a nonclinical population. A sample of 186 children aged eight to 18 years ( $49 \%$ female) provided information on maternal and self bodily pain, assessed by asking children about the presence and location of bodily pain experienced. Children also completed three laboratory pain tasks and reported on cold pressor pain intensity, pressure pain intensity and heat pain intensity. The presence of child-reported maternal pain was consistently correlated with daughters' bodily and laboratory pain, but not with sons' pain in bivariate analyses. Multivariate analyses controlling for child age and maternal psychological distress indicated that children of mothers with bodily pain reported more total bodily pain sites as well as greater pressure and cold pain intensity, relative to children of mothers without bodily pain. For cold pain intensity, these results differed for boys versus girls, in that daughters reporting maternal pain evidenced significantly higher cold pain intensity compared with daughters not reporting maternal pain. No such differences were found for boys. The findings suggest that children's perceptions of maternal pain may play a role in influencing children's own experience of pain, and that maternal pain models may affect boys and girls differently.

Key Words: Children; Pain; Sex differences; Social learning

\section{Lien entre les perceptions des enfants quant à la douleur maternelle et quant à leur propre douleur en laboratoire et hors du laboratoire}

Des recherches précédentes ont confirmé l'existence de liens entre la douleur qu'éprouvent parents et enfants. Par contre, on en sait peu sur les liens spécifiques au sexe quant à la douleur chez les parents et les enfants dans une population non clinique. Un échantillon de 186 enfants âgés de 8 à 18 ans (49\% de sexe féminin) ont fourni des données sur la douleur physique maternelle et auto-rapportée. Pour ce faire, on a interrogé les enfants sur la présence et la localisation de la douleur physique éprouvée. Les enfants ont aussi accompli trois tâches liées à la douleur en laboratoire, soit intensité de la douleur au froid, de la douleur à la pression et de la douleur à la chaleur. La présence de douleur maternelle signalée par l'enfant a été en constante corrélation avec la douleur physique et la douleur en laboratoire des filles, mais non des fils lors d'analyses bivariées. Les analyses multivariées ajustées selon l'âge de l'enfant et la détresse psychologique de la mère ont indiqué que les enfants de mères atteintes de douleur physique signalaient un plus grand nombre de sites douloureux et une intensité plus grande de la douleur à la pression et au froid, par rapport aux enfants de mères ne présentant pas de douleur. Pour ce qui est de l'intensité de la douleur au froid, ces résultats étaient différents entre les garçons et les filles, en ce sens que les filles faisant état de douleur maternelle ont signalé une intensité de la douleur au froid significativement plus marquée que les filles ne faisant pas état de douleur maternelle. Cette différence n'a pas été observée chez les garçons. Cette observation laisse supposer que les perceptions des enfants quant à la douleur maternelle peut jouer un rôle dans leur propre expérience douloureuse et que les modèles douloureux maternels peuvent affecter différemment les garçons et filles.

between child juvenile arthritis and parent pain history (2), with higher levels of parent bodily pain correlated with higher levels of child arthritis pain. Studies have also shown relationships between child and parent headache and migraine $(3,5,6)$, and child fibromyalgia and multiple chronic pain conditions in parents (1). A number of related studies focusing on parental chronic pain provide further evidence for parent-child pain relationships. Parents with chronic pain conditions appear more likely than healthy parents to have children who report pain $(12,13)$.

Research has also elucidated associations between child pain and parent mental health in the context of parent pain. Studies have found relationships between child functional abdominal pain and mothers' irritable bowel syndrome, maternal anxiety and depression (4), as well as between child migraine and recurrent abdominal pain, and maternal migraine and depression (14). These findings underscore the importance of accounting for parental mental health when examining the relationship dren with existing pain conditions have reported relationships

\footnotetext{
Pediatric Pain Program, Department of Pediatrics, David Geffen School of Medicine, University of California Los Angeles, Los Angeles,

California, USA

Correspondence: Dr Subhadra Evans, Pediatric Pain Program, Department of Pediatrics, David Geffen School of Medicine at UCLA,

10940 Wilshire Boulevard, Suite 810, Los Angeles, California 90024, USA. Telephone 310-794-2936, fax 310-794-2954,

e-mailsuevans@mednet.ucla.edu
} 
between child and parent pain. Parent-child pain relationships may exist partly due to social learning of pain behaviours or to transmission of family stressors and distress (15). A clearer picture of the parent as a model for physical pain is possible by controlling for the role of parent psychological distress.

The observed association between child pain and various forms of parental pain suggests that children may model both general pain behaviour and precise symptoms (10). This notion has implications for children's wider pain sensitivity, raising the possibility that children learn an entire repertoire of pain responses from parents, including 'real-life' pain and experimental pain as assessed in the laboratory. Studies using cold pressor pain have reported correlations in cold pressor pain scores between children with rheumatoid arthritis and their parents (16). Another study found that healthy children's responses to the cold pressor task were related to maternal responding, such that children who viewed their mother exaggerating displays of pain had lower pain thresholds than did children whose mothers were not given instructions on how to respond (17). Two studies, neither involving children, have examined the relationship between family pain and young adults' experimental pain responses. In one (18), the number of family members with bodily pain was related to greater daily pain and counterintuitive finding of decreased pain intensity in response to the cold pressor task. However, the sample comprised adult college students, who may have other, more salient, nonfamily pain models.

The only other published study (19) examining the link between family pain and young adults' laboratory pain highlights significant sex differences in familial pain relationships. In this study, a positive family history of pain was related to increased pain episodes and sensitivity to experimental thermal pain only in females, not males. Most studies have failed to examine sex-specific family relationships despite the finding that females appear to be more sensitive to familial pain models compared with males (9). Specific mother-daughter and mother-son pain relationships may exist, with maternal behaviour most relevant for girls' pain sensitivity. A study (7) comparing the effect of mothers' pain-promoting behaviour on boys' versus girls' cold pressor pain found a relationship between maternal behaviour and girls' cold pressor pain responses, which did not hold for boys. Similarly, we recently reported (20) that parent anxiety sensitivity was related to child laboratory pain intensity through its contribution to child anxiety sensitivity in girls, but not in boys. Taken together, these findings point to a potential moderating effect of child sex on the relationship between maternal pain and children's pain.

To date, the relationship between parental pain history and healthy children's laboratory pain remains unexamined. Moreover, previous work has not studied possible sex-specific relationships between maternal pain and child pain. The present study aimed to test these associations. Given that children's pain responses likely reflect both general pain behaviour and precise pain symptoms from parental modelling, children's laboratory and nonlaboratory pain was assessed. Nonlaboratory pain was measured by children's responses to questions regarding the presence and location of general bodily pain. Consistent with previous research, we hypothesized a significant positive association between the perception of maternal pain and children's laboratory and nonlaboratory pain. We further posited that perceived maternal pain would be more consistently related to daughters' pain than sons' pain. Given the previously noted role of maternal mental health in children's pain $(4,14)$, we also controlled for maternal psychological functioning in mother-child pain relationships.

\section{Participants}

\section{METHOD}

The current sample was drawn from a larger sample of 240 children who participated in a study on the effects of sex and puberty on laboratory pain responses described previously (21). Twelve participants with substantial missing data were excluded from the final sample, as were 44 participants whose mothers did not complete the measure of maternal psychological distress (described below). The final sample was composed of 186 participants between eight and 18 years of age (mean [ $\pm \mathrm{SD}$ ] age $12.33 \pm 2.74$ years) with approximately equal numbers of girls $(n=92)$ and boys $(n=94)$. The child racial or ethnic composition was as follows: 44\% Caucasian, 23\% Hispanic, 12\% African-American, 8\% Asian or Pacific Islander and $13 \%$ other. Data on race or ethnicity of mothers were not collected. Data on maternal education revealed that mothers were relatively well educated, with $31 \% \quad(n=57)$ attaining a bachelor's degree, and $27 \%(n=51)$ attaining graduate professional training. There were no significant demographic differences between the current sample and those excluded from the original sample.

Participants were recruited from a major urban area through advertisements, mass mailing and classroom presentations. Telephone screening reduced an initial 489 interested individuals to 244 eligible participants, with four failing to complete the study due to time constraints $(n=3)$ and discomfort with being attached to the electrodes $(n=1)$. The University of California, Los Angeles Institutional Review board, as well as the Institutional Review boards for the recruitment sites, approved all recruitment and study procedures. The pain tasks have been previously performed with children without adverse effects, including the cold pressor task (22), pressure task (23) and a similar heat task (24). The Institutional Review board approved consent, and assent forms were completed by parents and children. Participants received a $\$ 30$ video store voucher and a t-shirt for their participation.

\section{Procedure}

The data originate from a larger dataset that has previously been described in detail $(21,25)$. The present paper is an analysis of a specific set of variables for the purpose of examining the relationship between maternal pain and children's laboratory and nonlaboratory pain. There was one laboratory testing session. Upon visiting the laboratory, children completed demographic and psychosocial questionnaires with an experimenter in a room adjacent to the laboratory. Mothers completed questionnaires either at home before the laboratory session or at the laboratory on the day of the session. Children and mothers were escorted to separate rooms, and had no contact until after the session. Two experimenters conducted the sessions; experimenters included five women and two men. A male experimenter conducted the study with eight participants, with female experimenters conducting the sessions on the other occasions. There were no differences between boys and girls in the presence of male versus female experimenters $(\mathrm{P}=0.28$, Fisher's exact test).

After completing the questionnaires, children were escorted to the laboratory where they completed cold pressor, 
thermal heat and cutaneous pressure tasks (described below). Before the administration of the pain tasks, children were instructed on the use of a vertical sliding visual analogue scale (VAS) for rating pain intensity. Four-trial blocks of cutaneous pressure and thermal pain stimuli, and two cold pressor trials were presented separately in counter-balanced order across participants. Preliminary analyses tested for order effects; none were found. For each task, pain intensity was assessed by asking participants to rate their pain using a VAS. Further information regarding the laboratory events has been reported previously $(21,26)$.

\section{Laboratory pain tasks}

Cold pressor task: Participants underwent two trials with $10^{\circ} \mathrm{C}$ water using a commercial ice chest measuring $38 \mathrm{~cm}$ $\times 71 \mathrm{~cm} \times 35 \mathrm{~cm}$. A plastic mesh screen separated crushed ice from a plastic large-hole mesh armrest in the cold water. Water was circulated through the ice by a pump to prevent local warming around the hand. In the first trial, participants were instructed to keep the dominant hand in cold water to a depth of $5 \mathrm{~cm}$ above the wrist for as long as they could. The children were not informed about the trial ceiling of $3 \mathrm{~min}$ because this was a tolerance task to examine their pain tolerance to the cold water. The second cold pressor task had an informed ceiling of $1 \mathrm{~min}$ in which children were told to keep their hand in the cold water as long as they could, but at $1 \mathrm{~min}$ would be asked to remove their hand from the water. This was a task intended to examine pain ratings within a similar time frame and also to examine socialized demand characteristics on children's pain. The 1 min informed ceiling pain task was chosen to further examine socialization roles. The longer uninformed pain tolerance cold pressor task has been previously reported in another study (26) that examined the roles of anxiety sensitivity, heart rate, sex and puberty on pain tolerance.

Pressure task: The Ugo Basile Analgesy-Meter 37215 (Ugo Basile Biological Research Apparatus, Italy) was used to administer focal pressure through a lucite point approximately $1.5 \mathrm{~mm}$ in diameter to the second dorsal phalanx of the middle finger and index finger of each hand. Four trials, two at each of two levels of pressure ( $322.5 \mathrm{~g}$ and $465 \mathrm{~g}$ ), were run with an uninformed ceiling of $3 \mathrm{~min}$. Participants were instructed that they would experience pressure and to leave their finger in place for as long as possible, and they were free to remove the weight at any time.

Thermal heat task: The Ugo Basile 7360 Unit (Ugo Basile Biological Research Apparatus, Italy) was used to administer four trials of two infrared stimulus intensities $(15,20)$ of radiant heat $5 \mathrm{~cm}$ proximal to the wrist and $7.5 \mathrm{~cm}$ distal to the elbow on both volar forearms with an uninformed ceiling of $20 \mathrm{~s}$. Participants were informed that the task would involve heat and some discomfort, shown where to place their forearm and told they could move their arm away at any time.

Pain intensity: The VAS was rated using a vertical slider, which was anchored with 0 at one end, and 10 at the other. The scale also included corresponding colour cues, from white to dark red. The VAS is brief, easily understood and possesses excellent psychometric properties (27). Pain intensity was assessed immediately after each trial by asking participants to use the VAS to rate the amount of pain they experienced during the task. Children were asked "at its worst, how much pain did you feel?" Bodily pain assessment: Using an interview format, children were asked by the experimenter whether they currently had any pain problems (ie, "Do you have any pain problems right now? [headaches, stomach aches, fibromyalgia, back pain, other]" [yes/no]). If children answered 'yes' they were further asked to list where they experienced pain using an open-ended format (ie, "Where is the pain? [what part of your body]?"). The total number of body locations was then calculated by summing the number of pain locations listed by the child. This was adapted from the Varni-Thompson pain questionnaire (28) and has been used in the authors' pain clinic for over 10 years. The child's report of maternal pain followed a similar format; children were asked whether anyone in their family experienced pain (ie, "Does anyone in your family who lives at home with you have any pain problems now?" [yes/no]). If children answered affirmatively, they were asked who in their family currently experienced pain and to list the family members' type of pain and pain location(s) (ie, "What type of pain do they have/where is it? [headaches, back pain, fibromyalgia, etc]"]. Thus, children's responses detailed the presence of maternal bodily pain as well as type and location of the pain, with a total score formed by summing the number of body locations listed by the child.

Symptom Checklist-90-R (SCL-90): Mothers completed this widely used instrument of psychological functioning. The checklist measures nine dimensions, including interpersonal sensitivity, obsessive-compulsive, depression, somatization, anxiety, hostility, phobic anxiety, paranoid ideation and psychoticism. Items are scored on a five-point scale of stress ranging from 'not at all' to 'extremely.' Good internal consistency ( $\alpha$ range $=0.77$ to 0.90$)$ and adequate test-retest reliability (range 0.68 to 0.83 over 10 weeks) have been reported (29). Three global scores are available - the positive symptom distress index, which measures intensity of psychological distress, was used in the present study. Scores range from 0 (not at all) to 4 (extremely).

Demographic information questionnaire: An authordeveloped demographic information questionnaire was completed by mothers. The questionnaire assessed demographic information about the child, including age, sex, race or ethnicity, and demographic information about the child's parents, including education attained. Education was assessed using five categories: did not complete high school, high school graduate, partial college, bachelor's degree and graduate training.

\section{Statistical analysis}

Independent samples $t$ tests for continuous data and $\chi^{2}$ tests for categorical data were used to examine mean differences between boys and girls on child age, bodily pain and laboratory pain, child-reported maternal bodily pain and maternal psychological distress. Point-biserial correlations were performed separately for boys and girls testing the association between maternal bodily pain (yes/no) and children's total number of bodily pain sites, as well as children's experimental pain intensity. ANCOVAs using the formula 2 (sex: girls versus boys) $\times 2$ (child-reported maternal pain: no versus yes) on children's laboratory pain outcomes and the total number of children's bodily pain sites were conducted with the covariates child age and maternal psychological distress. Correlations for the entire sample revealed that age was associated with child pain outcomes $(\mathrm{r}=-0.15$ to $-0.34, \mathrm{P}<0.05)$ indicating that older age was associated with fewer bodily pain sites and lower laboratory pain intensity. Maternal psychological distress was also 
TABLE 1

Point-biserial correlations between maternal bodily pain and child pain outcomes presented separately for girls versus boys

\begin{tabular}{|c|c|c|c|c|c|c|}
\hline & \multicolumn{2}{|c|}{ Maternal variables } & \multicolumn{4}{|c|}{ Child pain } \\
\hline & $\begin{array}{c}\text { Mother pain } \\
\text { (yes/no) }\end{array}$ & $\begin{array}{l}\text { Mother } \\
\text { SCL-90 }\end{array}$ & $\begin{array}{c}\text { Bodily pain } \\
\text { (number of locations) }\end{array}$ & $\begin{array}{l}\text { Cold pain } \\
\text { intensity }\end{array}$ & $\begin{array}{l}\text { Heat pain } \\
\text { intensity }\end{array}$ & $\begin{array}{l}\text { Pressure pain } \\
\text { intensity }\end{array}$ \\
\hline \multicolumn{7}{|c|}{ Mother pain } \\
\hline Girls & 1 & $0.35^{\star \star}$ & $0.30^{\star *}$ & $0.27^{\star *}$ & $0.25^{\star}$ & $0.24^{*}$ \\
\hline Boys & & 0.19 & 0.13 & 0.05 & -0.02 & 0.01 \\
\hline \multicolumn{7}{|c|}{ Mother SCL-90 } \\
\hline Boys & & & -0.15 & $-0.22^{*}$ & $-0.31^{\star *}$ & -0.13 \\
\hline \multicolumn{7}{|c|}{ Child bodily pain } \\
\hline Girls & & & 1 & $0.26^{*}$ & $0.36^{\star \star}$ & $0.27^{\star *}$ \\
\hline Boys & & & & 0.13 & 0.15 & 0.01 \\
\hline \multicolumn{7}{|c|}{ Cold pain intensity } \\
\hline Boys & & & & & & $0.70^{* *}$ \\
\hline
\end{tabular}

${ }^{*} P<0.05 ;{ }^{*} P<0.01$. Presence of maternal pain was coded as 1 , absence of maternal pain as 0 . SCL-90 Symptom Checklist-90-R

TABLE 2

Demographic and pain information by child sex

\begin{tabular}{|c|c|c|}
\hline & Male, $n=94$ & Female, $n=92$ \\
\hline \multicolumn{3}{|l|}{ Child variables } \\
\hline Child age, years* & $12.14(2.79)$ & $12.52(2.69)$ \\
\hline \multicolumn{3}{|l|}{ Child pain, $\mathrm{n}(\%)$} \\
\hline Any pain & $31(33)$ & $36(39)$ \\
\hline Head & $16(17)$ & $20(22)$ \\
\hline Stomach & $7(7)$ & $13(14)$ \\
\hline Back and neck & $7(7)$ & $6(7)$ \\
\hline Legs and feet & $5(5)$ & $5(5)$ \\
\hline Arms and hands & $2(2)$ & $1(1)$ \\
\hline Other & $5(5)$ & $0(0)$ \\
\hline Total number of pain sites* & $0.48(0.83)$ & $0.56(0.79)$ \\
\hline Cold pain intensity VAS* & $4.01(2.98)$ & $3.95(3.18)$ \\
\hline Heat pain intensity VAS* & $5.05(2.78)$ & $5.22(2.63)$ \\
\hline Pressure pain intensity $\mathrm{VAS}^{*}$ & $4.83(2.52)$ & $5.29(2.72)$ \\
\hline \multicolumn{3}{|l|}{ Maternal variables } \\
\hline SCL-90 PSDI* & $1.31(0.48)$ & $1.26(0.41)$ \\
\hline \multicolumn{3}{|c|}{ Mother pain (child-reported), n (\%) } \\
\hline Any pain & $27(29)$ & $22(24)$ \\
\hline Head & $15(16)$ & $7(8)$ \\
\hline Stomach & $2(2)$ & $1(1)$ \\
\hline Back and neck & $8(9)$ & $13(14)$ \\
\hline Legs and feet & $3(3)$ & $2(2)$ \\
\hline Arms and hands & $1(1)$ & $3(3)$ \\
\hline Other & $3(3)$ & $1(1)$ \\
\hline
\end{tabular}

${ }^{*}$ Results presented as mean (SD). There were no significant differences between male and female children. Some individuals had more than one body pain location. PSDI Positive symptom distress index; SCL-90 Symptom Checklist-90-R; VAS Visual analogue scale significantly correlated with child laboratory and nonlaboratory pain (Table 1). Thus, all subsequent analyses controlled for child age and maternal psychological distress. Separate ANCOVAs were conducted for pain intensity ratings for each of the three pain tasks (ie, cold pressor, thermal heat and pressure) and child bodily pain.

Pain intensity ratings for the thermal and pressure tasks were highly correlated across the four trials within each task $(\mathrm{r}=0.53$ to $0.89, \mathrm{P}<0.001)$ and were therefore averaged across the four trials within each task, yielding a single mean value for pressure intensity and heat intensity. The single pain intensity rating for the 1 min cold pressor trial was used to analyze children's responses to this task.

\section{RESULTS}

Demographic and pain information

Table 2 presents descriptive data for the bodily pain and laboratory pain outcomes, including the total number of pain sites for children. Boys listed between zero and four body locations affected by pain and girls listed between zero and three body locations affected by pain. One-third of boys and almost $40 \%$ of girls reported pain in at least one body location. Tests of sex differences $\left(\chi^{2}\right.$ for categorical data and $t$ tests for continuous data) failed to reveal any significant differences between boys and girls on presence of pain (yes/no response) or location of bodily pain (such as head, stomach, etc, as listed by children in the interview).

There were no differences between mothers of sons versus mothers of daughters on presence of pain, pain sites listed or psychological distress scores. Scores on the SCL-90 revealed that mothers reported being distressed by psychological symptoms between 'a little bit' and 'moderately,' consistent with nonclinical populations. Biserial correlations were performed between children's reports of maternal pain (yes/no) and mother's SCL-90 somatization scores. Significant moderate associations emerged between girls' reports of maternal pain 
TABLE 3

Results of ANCOVAs on the marginal means for child pain outcomes controlling for age and maternal psychological functioning

\begin{tabular}{|c|c|c|c|c|c|}
\hline \multirow{3}{*}{$\begin{array}{l}\text { Child pain outcomes } \\
\text { Cold pain intensity } \\
(0-10 \text { rating })\end{array}$} & \multirow{2}{*}{$\begin{array}{l}\text { Independent variables } \\
\text { Child sex }\end{array}$} & \multicolumn{2}{|l|}{ Marginal mean (SE) } & \multirow{2}{*}{$\frac{\mathbf{F}(\mathbf{d f})}{1.34(1)}$} & \multirow{2}{*}{$\frac{\mathbf{P}}{0.25}$} \\
\hline & & Girl & $4.71(0.40)$ & & \\
\hline & & Boy & $4.08(0.38)$ & & \\
\hline & Mother pain & No pain & $3.76(0.27)$ & $4.90(1)$ & 0.02 \\
\hline & & Pain & $5.02(0.49)$ & & \\
\hline & Sex $\times$ mother pain & Girl no mother pain & $3.53(0.39$ & $4.00(1)$ & 0.04 \\
\hline & & Girl mother pain & $5.89(0.71)$ & & \\
\hline & & Boy no mother pain & $4.00(0.35)$ & & \\
\hline & & Boy mother pain & $4.15(0.60)$ & & \\
\hline \multirow{8}{*}{$\begin{array}{l}\text { Pressure pain intensity } \\
\qquad(0-10 \text { rating })\end{array}$} & Child sex & Girl & $5.93(0.33)$ & $5.84(1)$ & 0.02 \\
\hline & & Boy & $4.84(0.31)$ & & \\
\hline & Mother pain & No pain & $4.90(0.23)$ & $4.36(1)$ & 0.04 \\
\hline & & Pain & $5.89(0.41)$ & & \\
\hline & Sex $\times$ mother pain & Girl no mother pain & $5.11(0.32)$ & $2.20(1)$ & 0.14 \\
\hline & & Girl mother pain & $6.76(0.59)$ & & \\
\hline & & Boy no mother pain & $4.69(0.32)$ & & \\
\hline & & Boy mother pain & $4.99(0.54)$ & & \\
\hline \multirow{8}{*}{$\begin{array}{l}\text { Heat pain intensity } \\
(0-10 \text { rating })\end{array}$} & Child sex & Girl & $5.72(0.33)$ & $1.97(1)$ & 0.16 \\
\hline & & Boy & $5.09(0.31)$ & & \\
\hline & Mother pain & No pain & $4.97(0.22)$ & $3.50(1)$ & 0.06 \\
\hline & & Pain & $5.84(0.40)$ & & \\
\hline & Sex $\times$ mother pain & Girl no mother pain & $4.94(0.32)$ & 2.33 & 0.13 \\
\hline & & Girl mother pain & $6.50(0.58)$ & & \\
\hline & & Boy no mother pain & $5.00(0.31)$ & & \\
\hline & & Boy mother pain & $5.18(0.54)$ & & \\
\hline \multirow{8}{*}{$\begin{array}{l}\text { Child bodily pain } \\
\text { (number of pain } \\
\text { locations) }\end{array}$} & Child sex & Girl & $0.72(0.10)$ & $4.26(1)$ & 0.04 \\
\hline & & Boy & $0.49(0.01)$ & & \\
\hline & Mother pain & No pain & $0.41(0.07)$ & $7.02(1)$ & 0.01 \\
\hline & & Pain & $0.80(0.12)$ & & \\
\hline & Sex $\times$ mother pain & Girl no mother pain & $0.43(0.10)$ & $1.92(1)$ & 0.17 \\
\hline & & Girl mother pain & $1.01(0.18)$ & & \\
\hline & & Boy no mother pain & $0.39(0.01)$ & & \\
\hline & & Boy mother pain & $0.58(0.17)$ & & \\
\hline
\end{tabular}

Note: Higher visual analogue scale scores denote increasing pain intensity. df Degrees of freedom

and mother's somatization scores $(\mathrm{r}=0.44, \mathrm{P}<0.001)$, and between boys' reports of maternal pain and mother's somatization $(r=0.32, P<0.01)$. These findings provide support for the use of children's reports of maternal pain, which are moderately associated with maternal perceptions of somatization.

Correlations between mother and child pain by sex

As shown in Table 1, separate biserial correlations for girls and boys were performed examining the relationship between child-reported maternal pain (yes/no) and child bodily pain (total number of pain sites), as well as child laboratory pain intensity. There were notable sex differences in these correlations. Presence of child-reported maternal pain was correlated with all daughter pain outcomes, including number of pain sites, and cold, pressure and heat intensity. In contrast, presence of child-reported maternal pain was not associated with any pain outcomes in sons. Presence of bodily pain in children was correlated with children's laboratory pain intensity in girls only and not in boys.
Multivariate analyses of child sex and maternal pain on child pain outcomes

Results of the ANCOVAs, controlling for child age and maternal psychological distress, on children's bodily pain and laboratory pain intensity are shown in Table 3. Marginal means with results from post hoc Sidak tests for each pain outcome are presented in Table 3.

For child bodily pain, the main effects of sex and maternal pain were significant $(\mathrm{F}=4.26$ and $\mathrm{F}=7.02$, respectively, $\mathrm{P}<0.05)$. Girls reported more total bodily pain sites compared with boys. In addition, children of mothers with bodily pain reported a greater number of total bodily pain sites compared with children of mothers without bodily pain.

For cold pain intensity, the main effect of maternal pain was significant. Children who reported mothers with pain were more likely to have higher cold pain intensity scores $(\mathrm{F}=4.90, \mathrm{P}<0.05)$. The sex $\times$ maternal pain interaction was also significant $(F=4.00$, $\mathrm{P}<0.05)$ and is presented in Figure 1. Analysis of simple effects revealed that, relative to girls reporting no maternal pain, girls 


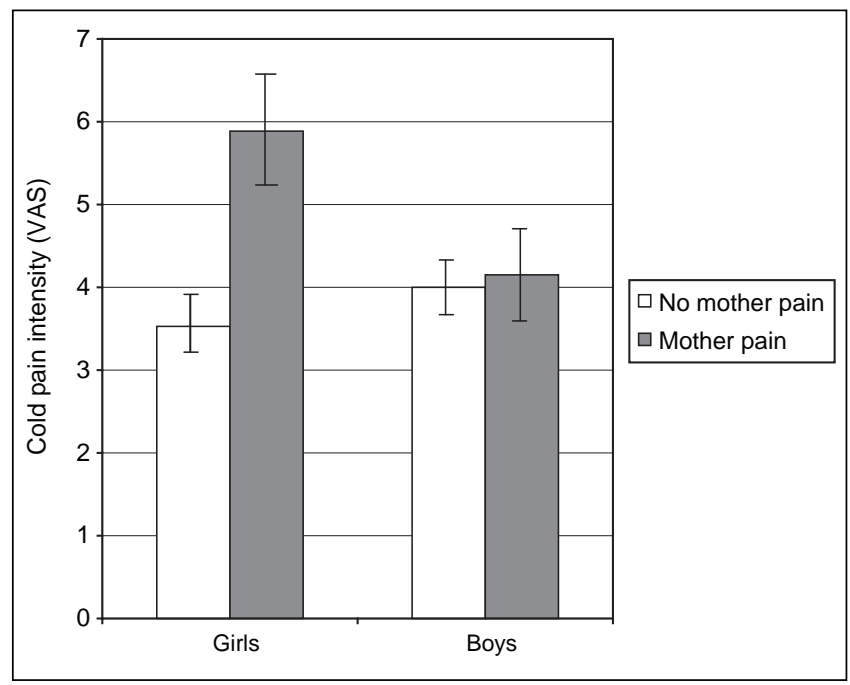

Figure 1) Interaction between child sex and maternal pain for cold pain intensity depicted for girls versus boys. VAS Visual analogue scale

who endorsed maternal pain evidenced significantly higher cold pain intensity $(\mathrm{F}=8.38, \mathrm{P}<0.05)$. There were no such differences for boys.

For pressure pain intensity, both main effects of sex and maternal pain were significant. Girls were more likely to report higher pressure pain than boys $(\mathrm{F}=5.84, \mathrm{P}<0.05)$ and children of both sexes who reported their mothers had pain were more likely to have higher pressure pain scores $(\mathrm{F}=4.36, \mathrm{P}<0.05)$. Despite a trend indicating girls with maternal pain reported the highest level of pressure pain, the interaction was not significant.

There were no main or interaction effects of sex and maternal pain for heat pain intensity. The covariates age $(\mathrm{F}=26.58$, $\mathrm{P}=0.00)$ and maternal psychological distress $(\mathrm{F}=4.89, \mathrm{P}=0.03)$ were found to be significant. With increasing age, children were less likely to report heat pain, and higher maternal psychological distress scores were associated with higher heat pain in children. Maternal psychological distress was not significantly associated with any other child laboratory or nonlaboratory pain outcomes.

\section{DISCUSSION}

The current findings support our hypotheses of significant associations between the presence of child-reported bodily pain in mothers and indexes of children's laboratory and nonlaboratory pain. Thus, multivariate results controlling for child age and maternal psychological distress revealed that child perceptions of maternal pain were linked to a greater number of self-reported bodily pain sites in children, as well as to heightened laboratory cold and pressure pain intensity among children. The relationship between maternal pain and children's cold pain intensity, however, differed depending on the sex of the child. These findings provide support for our hypotheses that maternal pain would be more closely related to daughters' than to sons' pain. Girls of mothers with child-reported bodily pain experienced greater cold pain intensity than girls of mothers without bodily pain (Figure 1 ). This difference did not hold for boys, who responded to the cold pressor tasks similarly regardless of mothers' pain status. On the other hand, our results did not support the hypothesized effect of maternal pain on children's laboratory heat pain intensity. Nor did we find significant sex differences in the mother-child pain relationship for any of the child pain indices other than cold pain intensity. Our overall findings are consistent with previous research pointing to relationships between maternal and child pain $(4,12,14,17)$.

It is not uncommon for studies using multiple laboratory tasks to find different results for the tasks, which likely reflects distinct pain processing pathways for cold, pressure and heat pain $(21,30)$. We found a main effect of child perceptions of maternal pain for all pain outcomes apart from heat pain. Heat is a very rapid, intense stimuli whereas the cold and pressure tasks involve a slower building of stimuli. Perhaps maternal pain is most relevant for gradual pain tasks, during which children may have the opportunity to call on parent-modelled coping. Furthermore, we found interaction effects only for cold pain. Cold pain is believed to be similar to the sensation of acute, clinical pain (22). In addition, the informed cold trial involved an element of expectation as children were aware of the task ceiling. It may be the case that mother-modelled pain responses are especially pertinent for girls undergoing acute, clinical pain or pain involving social expectation, whereas maternal pain models affect boys and girls equally for other forms of pain, including ongoing bodily pains.

The descriptive findings revealed that a number of children reported pain in at least one body area. Approximately onethird of boys and $40 \%$ of girls reported bodily pain. These findings are similar to larger epidemiological studies indicating between one-third and 50\% of children report pain (31-33), with many children reporting pain severe enough to cause functional disability (34). However, our measure of child pain was limited in that pain severity, duration and functional disability were not assessed. Nevertheless, the findings suggest that our sample is relatively consistent with large-scale population studies and that many children report pain.

Bivariate analyses revealed a number of interesting differences between boys and girls. Child perceptions of maternal pain were consistently linked to bodily and laboratory pain for girls, yet no such associations were revealed for boys. In addition, there were differences between boys and girls in the relationship between child bodily and laboratory pain. For girls, the number of body sites affected by pain was significantly correlated with their cold, pressure and heat pain. However, boys' body pain was unrelated to laboratory responses. This suggests that pain behaviour adopted by girls may involve a wider range of pain situations, whereas boys relate to pain in a more situation-specific manner. Although untested here, an extension of this finding is that girls may be more prone to learn a wider range of pain behaviours than boys. Thus, pain seen in mothers at home may translate as pain across multiple settings and for a variety of pain types for girls. Further research is needed to identify how parent pain models may affect general pain behaviour and precise symptoms differently for girls versus boys.

A main effect of child sex was revealed for pressure pain and child bodily pain. After controlling for child age and maternal psychological distress, girls reported higher pressure pain and a greater number of body locations affected by pain compared with boys. The findings stress the importance of accounting for child age in examining sex differences in pain, because tests performed on the raw data indicated no such differences (Table 2). Although sex differences in adult pain populations are fairly consistent (35), findings for healthy children's sex 
differences in pain and somatization are less clear (36), particularly for laboratory pain tasks (30) and in preadolescent children (37)

We also accounted for the role of maternal psychological distress in our analyses. Studies have found parental mental health to play a role in children's pain and health $(38,39)$ along with parental physical health $(4,14)$. In multivariate analyses, we only found a role for maternal psychological distress in child heat pain intensity, which, unlike the other child pain outcomes, was unrelated to child perceptions of maternal pain. It is possible that the heat task involves specific demands related to models of psychological rather than physical functioning.

Overall, the findings make a number of unique contributions to the literature on family pain predictors of children's pain. In particular, it appears that child perceptions of maternal pain may be especially important in understanding girls' pain behaviour. The results consequently highlight the importance of considering individual family members as pain models. Rather than grouping mothers, fathers and other family members together in examining family history of pain, it may be fruitful to examine each independent role. Likewise, studies grouping children together can circumvent important differences in the way girls and boys view and adopt pain behaviour. The present study also emphasizes the value in considering varied pain responses, including everyday and experimental pain.

A limitation of the present study is the failure to include parental experimental pain. It is likely that additional parentchild pain relationships would have emerged had we examined mother's responses to the cold, heat and pressure tasks. A study is currently underway in our laboratory to address this very limitation, wherein mother laboratory pain responses will be assessed. Another limitation of the present study was the limited measurement of bodily pain; it is likely that more complete information, such as frequency and intensity of pain episodes, would have yielded richer findings, as would a standardized, well-validated measure of child pain. In addition, we

\section{REFERENCES}

1. Schanberg LE, Keefe FJ, Lefebvre JC, Kredich DW, Gil KM. Social context of pain in children with Juvenile Primary Fibromyalgia Syndrome: Parental pain history and family environment. Clin J Pain 1998;14:107-15.

2. Schanberg LE, Anthony KK, Gil KM, Lefebvre JC, Kredich DW, Macharoni LM. Family pain history predicts child health status in children with chronic rheumatic disease. Pediatrics 2001;108:E47.

3. Aromaa M, Rautava P, Helenius H, Sillanpää ML. Factors of early life as predictors of headache in children at school entry. Headache 1998;38:23-30

4. Campo JV, Bridge J, Lucas A, et al. Physical and emotional health of mothers of youth with functional abdominal pain. Arch Pediatr Adolesc Med 2007;161:131-7.

5. Kroner-Herwig B, Heinrich M, Morris L. Headache in German children and adolescents: A population-based epidemiological study. Cephalalgia 2007;27:519-27.

6. Laurell K, Larsson B, Eeg-Olofsson O. Headache in schoolchildren: Association with other pain, family history and psychosocial factors. Pain 2005;119:150-8.

7. Chambers CT, Craig KD, Bennett SM. The impact of maternal behavior on children's pain experiences: An experimental analysis. J Pediatr Psychol 2002;27:293-301.

8. Violon A, Giurgea D. Familial models for chronic pain. Pain 1984;18:199-203.

9. Edwards PW, Zeichner A, Kuczmierczyk AR, Boczkowski J. Familial pain models: The relationship between family history of pain and current pain experience. Pain 1985;21:379-84. did not assess fathers' pain responses, and consistent with gender role theory (40), it is possible that fathers' pain is especially important for sons' pain responses. Child age may also impact on the salience of parental models. Although we controlled for age effects in analyses, it is possible that the wide range in children's ages bypassed important developmental changes. A further limitation is the sole reliance on children's reports of maternal and self pain. Although it is important to assess the child's view of parental pain, because this taps into their awareness of the parent pain as a salient model, it is possible that mothers' own reports of pain would have resulted in different findings. An additional area of interest would be to examine sex-specific parent pain models in experimental pain for children with chronic pain. Different mechanisms may operate for healthy versus clinical pain populations.

\section{CONCLUSIONS}

The present study was an attempt to understand sex-specific relationships between healthy children's perceptions of maternal pain and children's pain, as assessed through self-reported bodily pain and responses to brief controlled laboratory pain stimuli. Our findings lend support to sex-specific mother-child pain relationships; in particular, the relationship between mother and daughter pain. This is the first time that such associations have been examined in mothers of healthy children as pain models and children's bodily and laboratory pain. The findings provide further support for the social learning of pain in children and potentially shed light on the divergent pain learning systems of boys and girls. Research is needed to further examine the roles of parent and child sex, and family pain in children's pain responsivity. An important future application of the literature is the testing and implementation of family interventions that might allow for parental modelling of healthful behaviour.

ACKNOWLEDGEMENTS: The present study was supported by 2R01DE012754 (PI: Lonnie K Zeltzer) awarded by the National Institute of Dental and Craniofacial Research.

10. Osborne RB, Hatcher JW, Richtsmeier AJ. The role of social modeling in unexplained pediatric pain. J Pediatr Psychol 1989;14:43-61.

11. Walker LS, Garber J, Greene JW. Psychosocial correlates of recurrent childhood pain: A comparison of pediatric patients with recurrent abdominal pain, organic illness, and psychiatric disorders. J Abnorm Psychol 1993;102:248-58.

12. Evans S, Keenan TR, Shipton EA. Psychosocial adjustment and physical health of children living with maternal chronic pain. J Paediatr Child Health 2007;43:262-70.

13. Mikail SF, von Baeyer CL. Pain, somatic focus, and emotional adjustment in children of chronic headache sufferers and controls. Soc Sci Med 1990;31:51-9.

14. Mortimer MJ, Kay J, Jaron A, Good PA. Does a history of maternal migraine or depression predispose children to headache and stomach-ache? Headache 1992;32:353-5.

15. Saunders K, Korff MV, Leresche L, Mancl L. Relationship of common pain conditions in mothers and children. Clin J Pain 2007;23:204-13.

16. Thastum M, Zachariae R, Scholer M, Bjerring P, Herlin T. Cold pressor pain: Comparing responses of juvenile arthritis patients and their parents. Scand J Rheumatol 1997;26:272-9.

17. Goodman JE, McGrath PJ. Mothers' modeling influences children's pain during a cold pressor task. Pain 2003;104:559-65.

18. Zeichner A, Widner S, Loftin M, Panopoulos G, Allen J. Effects of familial pain models on daily pain indices and performance during the cold pressor task. Psychol Rep 1999;84:955-60. 
19. Fillingim RB, Edwards RR, Powell T. Sex-dependent effects of reported familial pain history on recent pain complaints and experimental pain responses. Pain 2000;86:87-94.

20. Tsao JC, Lu Q, Myers CD, Kim SC, Turk N, Zeltzer LK. Parent and child anxiety sensitivity: Relationship to children's experimental pain responsivity. J Pain 2006;7:319-26.

21. Lu Q, Zeltzer LK, Tsao JC, Kim SC, Turk N, Naliboff BD. Heart rate mediation of sex differences in pain tolerance in children. Pain 2005; 118:185-93

22. von Baeyer CL, Piira T, Chambers CT, Trapanotto M, Zeltzer LK. Guidelines for the cold pressor task as an experimental pain stimulus for use with children. J Pain 2005;6:218-27.

23. Walco G, Dampier CD, Hartstein G, Djordjevic D, Miller L. The relationship between recurrent clinical pain and pain threshold in children. In: Krane DC, ed. Advances in Pain Research Therapy. New York: Raven, 1990:333-40.

24. Meier PM, Berde CB, DiCanzio J, Zurakowski D, Sethna NF. Quantitative assessment of cutaneous thermal and vibration sensation and thermal pain detection thresholds in healthy children and adolescents. Muscle Nerve 2001;24:1339-45

25. Tsao JC, Myers CD, Craske MG, Bursch B, Kim SC, Zeltzer LK. Role of anticipatory anxiety and anxiety sensitivity in children's and adolescents' laboratory pain responses. J Pediatr Psychol 2004;29:379-88.

26. Tsao JC, Lu Q, Kim SC, Zeltzer LK. Relationships among anxious symptomatology, anxiety sensitivity and laboratory pain responsivity in children. Cogn Behav Ther 2006;35:207-15.

27. Gragg RA, Rapoff MA, Danovsky MB, et al. Assessing chronic musculoskeletal pain associated with rheumatic disease: Further validation of the pediatric pain questionnaire. J Pediatr Psychol 1996;21:237-50.

28. Varni JW, Thompson KL, Hanson V. The Varni/Thompson Pediatric Pain Questionnaire. I. Chronic musculoskeletal pain in juvenile rheumatoid arthritis. Pain 1987;28:27-38.
29. Derogatis LR. The Brief Symptom Inventory (BSI): Administration, Scoring and Procedures Manual, 3rd edn. Minneapolis: National Computer Systems, 1993

30. Myers CD, Tsao JC, Glover DA, Kim SC, Turk N, Zeltzer LK. Sex, gender, and age: Contributions to laboratory pain responding in children and adolescents. J Pain 2006;7:556-64.

31. Roth-Isigkeit A, Thyen U, Raspe HH, Stoven H, Schmucker P. Reports of pain among German children and adolescents: An epidemiological study. Acta Paediatr 2004;93:258-63.

32. Perquin CW, Hazebroek-Kampschreur AA, Hunfeld JA, et al. Pain in children and adolescents: A common experience. Pain 2000;87:51-8.

33. Mikkelsson M, Salminen JJ, Kautiainen H. Non-specific musculoskeletal pain in preadolescents. Prevalence and 1-year persistence. Pain 1997;73:29-35.

34. Roth-Isigkeit A, Thyen U, Stoven H, Schwarzenberger J, Schmucker P. Pain among children and adolescents: Restrictions in daily living and triggering factors. Pediatrics 2005;115:e152-62.

35. Unruh AM. Gender variations in clinical pain experience. Pain 1996;65:123-67.

36. Unruh A, Campbell MA. Gender variation in children's pain experiences. In: Finley PJ, ed. Chronic and Recurrent Pain in Children and Adolescents. Seattle: IASP Press, 1999:199-241.

37. Tsao JC, Zeltzer LK. Sex differences in pain-related symptoms and self-initiated school nurse visits among pre-adolescents. J Pain Symptom Manage 2003;25:472-80.

38. Ramchandani PG, Fazel M, Stein A, Wiles N, Hotopf M. The impact of recurrent abdominal pain: Predictors of outcome in a large population cohort. Acta Paediatr 2007;96:697-701.

39. van Tilburg MA, Venepalli N, Ulshen M, Freeman KL, Levy R, Whitehead WE. Parents' worries about recurrent abdominal pain in children. Gastroenterol Nurs 2006;29:50-5.

40. Langlois JH, Downs AC. Mothers, fathers, and peers as socialization agents of sex-typed play behaviors in young children. Child Dev 1980;51:1237-47. 


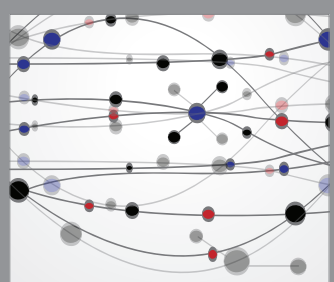

The Scientific World Journal
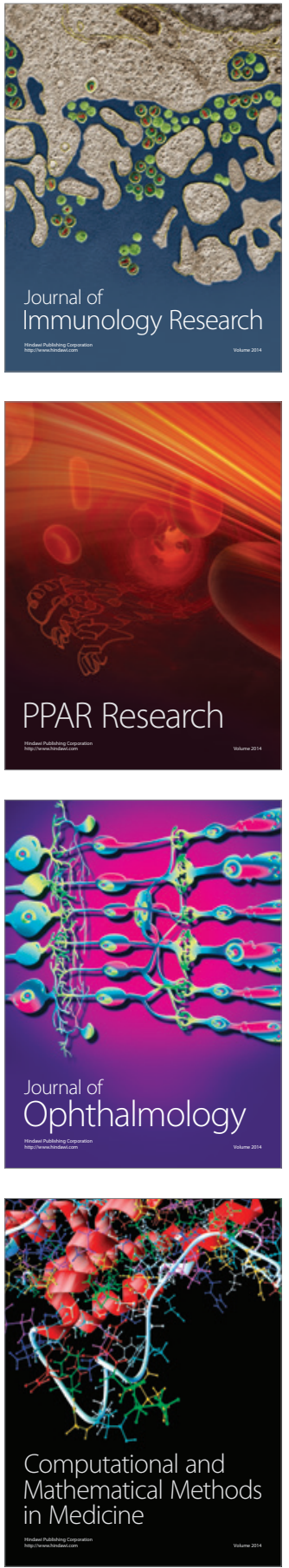

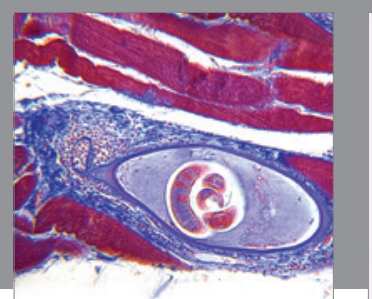

Gastroenterology Research and Practice

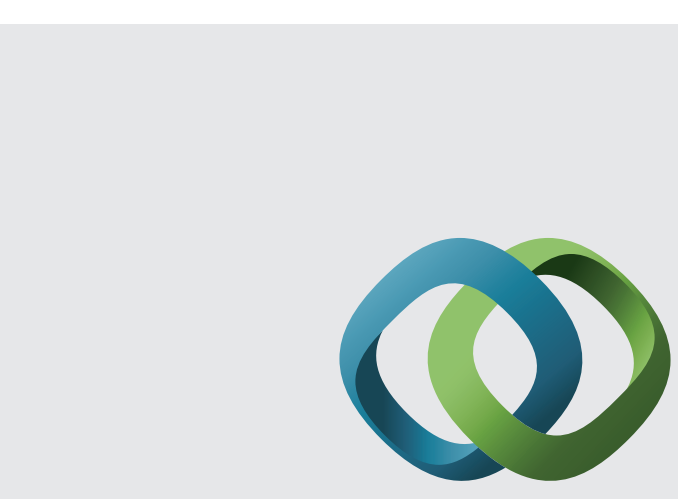

\section{Hindawi}

Submit your manuscripts at

http://www.hindawi.com
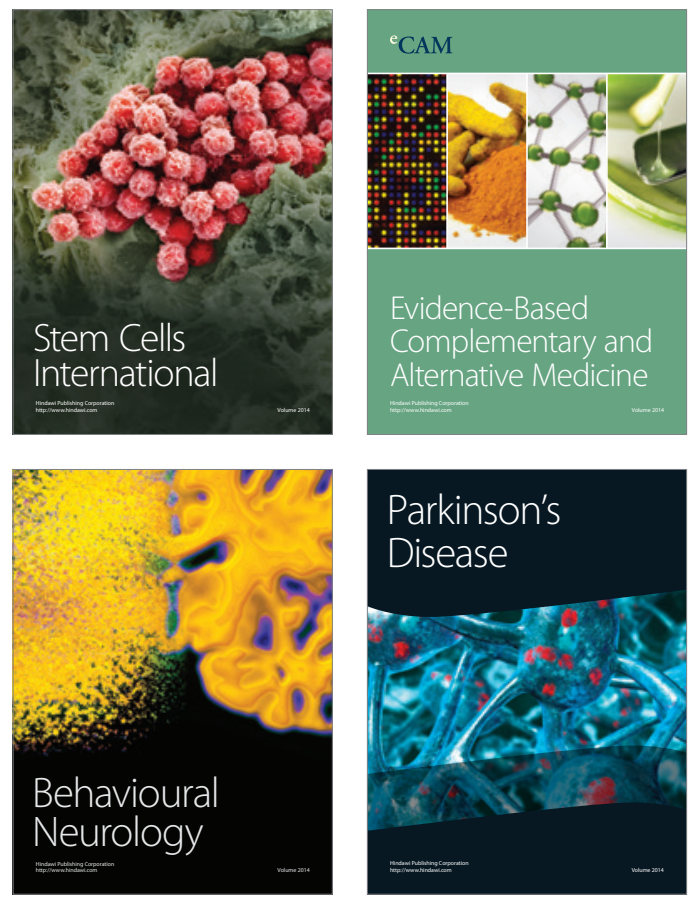
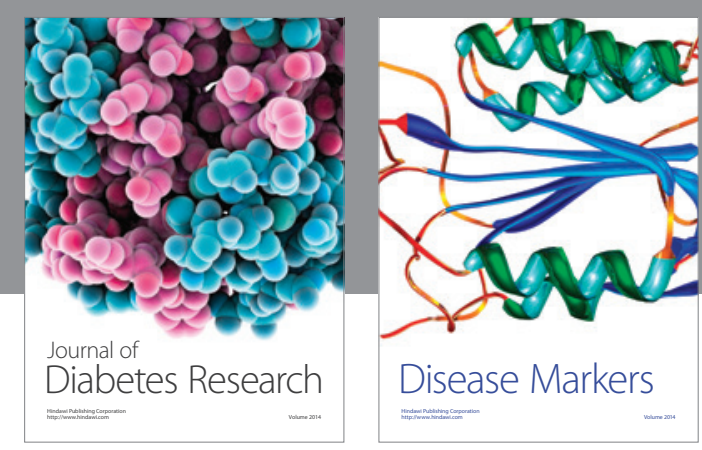

Disease Markers
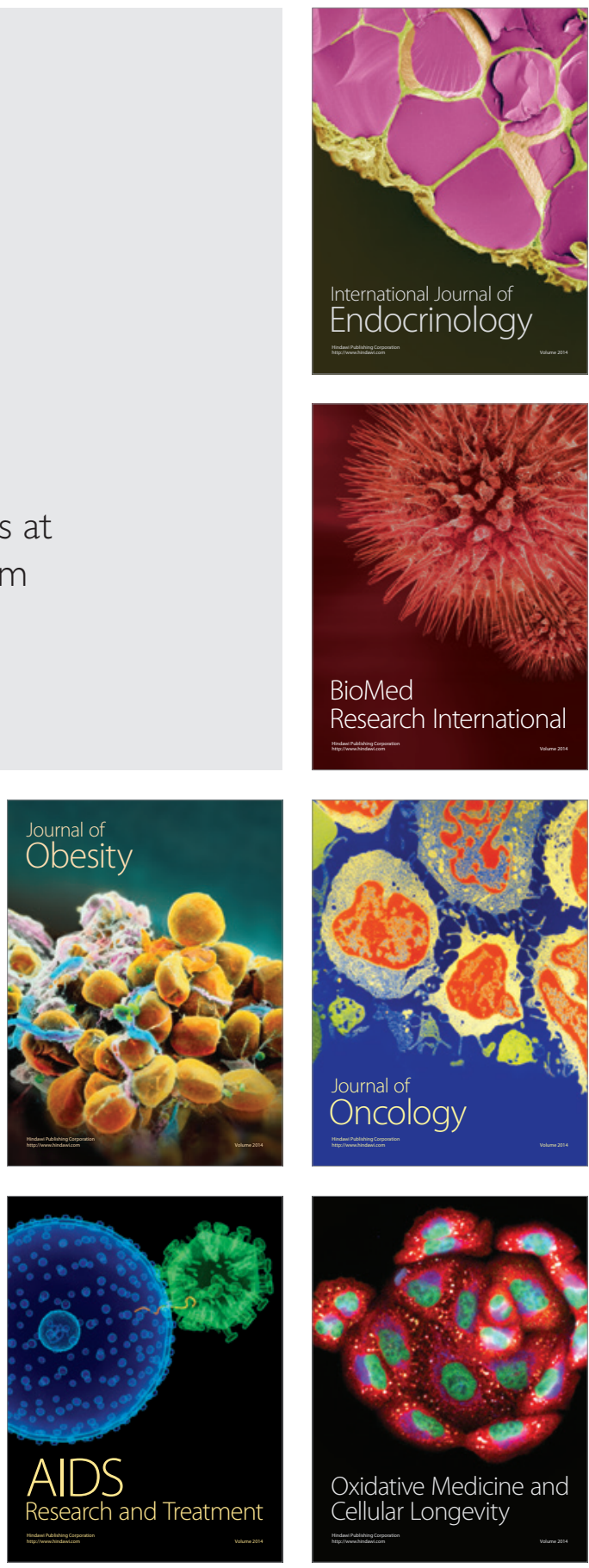